\title{
Deposition and re-erosion studies by means of local impurity injection in TEXTOR
}

A. Kirschner ${ }^{a^{*}}$, A. Kreter ${ }^{\text {a }}$, P. Wienhold ${ }^{\text {a }}$, S. Brezinsek ${ }^{\text {a }}$, J.W. Coenen ${ }^{\text {a }}$ H.G. Esser ${ }^{\text {a }}$, A. Pospieszczyk ${ }^{\mathrm{a}}$, Ch. Schulz ${ }^{\mathrm{a}}$, U. Breuer ${ }^{\mathrm{b}}$, D. Borodin ${ }^{\mathrm{a}}$, M. Clever ${ }^{\mathrm{a}}$, R. Ding ${ }^{\mathrm{c}, \mathrm{a}}$, A. Galonska ${ }^{\mathrm{a}}$, A. Huber ${ }^{\mathrm{a}}$, A. Litnovsky ${ }^{\mathrm{a}}$, D. Matveev ${ }^{\mathrm{a}, \mathrm{d}}$, K. Ohya ${ }^{\mathrm{e}}$, V. Philipps ${ }^{\mathrm{a}}$, U. Samm ${ }^{\mathrm{a}}$, O. Schmitz ${ }^{\mathrm{a}}$, B. Schweer ${ }^{\mathrm{a}}$, H. Stoschus ${ }^{\mathrm{a}}$, and TEXTOR team ${ }^{\mathrm{a}}$

${ }^{a}$ Institut für Energieforschung - Plasmaphysik, Forschungszentrum Jülich, Association EURATOMFZJ, Trilateral Euregio Cluster, D-52425 Jülich, Germany.

${ }^{b}$ Zentralabteilung für Chemische Analysen,Forschungszentrum Jülich, D-52425 Jülich, Germany.

${ }^{c}$ China Institute of Plasma Physics, Chinese Academy of Sciences, P.O. Box 1126, Hefei, Anhui 230031, P.R.China.

${ }^{d}$ Department of Applied Physics, Gent University, Rozier 44, B-9000 Gent, Belgium.

${ }^{e}$ Institute of Technology and Science, The University of Tokushima, Tokushima 770-8506, Japan.

\begin{abstract}
Pioneering experiments to study local erosion and deposition processes have been carried out in TEXTOR by injecting ${ }^{13} \mathrm{C}$ marked hydrocarbons $\left(\mathrm{CH}_{4}\right.$ and $\left.\mathrm{C}_{2} \mathrm{H}_{4}\right)$ as well as silane $\left(\mathrm{SiD}_{4}\right)$ and tungsten-hexafluoride $\left(\mathrm{WF}_{6}\right)$ through test limiters exposed to the edge plasma. The influence of various limiter materials $(\mathrm{C}, \mathrm{W}, \mathrm{Mo})$ and surface roughness, different geometries (spherical or roof-like) and local plasma parameters has been studied. Depending on these conditions the local deposition efficiency of injected species varies between $0.1 \%$ and $9 \%$ - the largest deposition has been found for ${ }^{13} \mathrm{CH}_{4}$ injection through unpolished, spherical $\mathrm{C}$ test limiter and ohmic plasma conditions. The most striking result is that ERO modelling cannot reproduce these low deposition efficiencies using the common assumptions on sticking probabilities and physical and chemical re-erosion yields. As an explanation large re-erosion due to background plasma and possibly low "effective sticking" of returning species is applied. This has been interpreted as enhanced re-erosion of re-deposits under simultaneous impact of high ion fluxes from plasma background.
\end{abstract}


PACS: 52.40.Hf, 52.77.Dq, 52.65.Pp

JNM keywords: Plasma-Materials Interaction, Redeposition, Surface Effects PSI-19 keywords: Erosion \& Deposition, Impurity transport, TEXTOR, ERO code

* Corresponding author address: Forschungszentrum Jülich (IEF-4), 52425 Jülich, Germany *Corresponding author E-mail: a.kirschner@fz-juelich.de 


\section{Introduction}

The build-up and re-erosion of re-deposits in fusion devices is of importance due to their potential of fuel retention and dust generation. In TEXTOR, extensive studies of local impurity transport and resulting deposition have been performed by injecting known amounts of various impurity molecules $\left(\mathrm{SiD}_{4},{ }^{13} \mathrm{CH}_{4},{ }^{13} \mathrm{C}_{2} \mathrm{H}_{4}\right.$ and $\left.\mathrm{WF}_{6}\right)$ through test limiters exposed to the edge plasma. Typical plasma parameters at the last closed flux surface (LCFS) in TEXTOR range from 30 to $80 \mathrm{eV}$ and $2 \times 10^{12}$ to $8 \times 10^{12} \mathrm{~cm}^{-3}$, depending on discharge conditions. Spectroscopy gives information about break-up products in the plasma. Postmortem analysis delivers information about layer composition and local deposition efficiency, i.e. amount of locally deposited atoms relative to the amount of injected atoms. Figure 1 shows the general set-up of the injection experiments in TEXTOR including photographs of typical spherical and roof-like test limiters to illustrate their geometry.

The present paper gives an overview of former tracer injection experiments with test limiters in TEXTOR using $\mathrm{SiD}_{4},{ }^{13} \mathrm{CH}_{4}$ and ${ }^{13} \mathrm{C}_{2} \mathrm{H}_{4}$. Also, new results from recent $\mathrm{WF}_{6}$ injection through test limiter are presented. In addition, to study deposition and re-erosion at remote areas with negligible ion flux impact, $\mathrm{CH}_{4}$ injection through a carrier front plate located deeply in the edge plasma has been carried out recently. The main experimental results will be discussed in comparison with modelling using the impurity transport code ERO, leading to important conclusions concerning re-erosion of re-deposits at plasma-wetted compared to remote areas. Possible impact for future fusion devices such as ITER will be discussed in the conclusions. An overview of ${ }^{13} \mathrm{CH}_{4}$ injection experiments including divertor experiments such as AUG, JET and DIII-D will be presented in [1]. 


\section{Overview of tracer injection experiments in TEXTOR}

\subsection{Silane injection through test limiter}

First tracer injection experiments at TEXTOR have been carried out in the beginning of the 1990 ies using silane, $\mathrm{SiD}_{4}$. Main aim of these experiments was to study whether local impurity injection can serve as an in-situ method to repair wall elements or reduce net erosion. A spherically shaped graphite test limiter has been exposed to the scrape-off-layer (SOL) applying ohmic plasmas [2]. The test limiter was located 5mm outside the LCFS. Within 7 discharges a known amount of $\mathrm{SiD}_{4}$ molecules $\left(2.4 \times 10^{19}\right.$ per discharge $)$ has been injected through a hole in the limiter surface applying $\mathrm{SiD}_{4}$ puff of about 1s. Light emission from $\mathrm{Si}^{+}$ions has been observed spectroscopically. The test limiter surface has been analysed after exposure by means of interference colour and Rutherford Backscattering analysis. The local $\mathrm{Si}$ deposition efficiency, i.e. number of deposited $\mathrm{Si}$ atoms on the limiter surface relative to number of injected $\mathrm{Si}$ atoms, has been estimated to $4-5 \%$.

A similar experiment has been carried out using a spherical stainless steel test limiter [3]. This time 10 discharges with smaller $\mathrm{SiD}_{4}$ injection rate of about $7 \times 10^{18}$ molecules per discharge have been performed. Post-mortem analysis applying colour fringe and electron probe microprobe analysis (EPMA) revealed a local Si deposition efficiency of less than $\mathbf{5 \%}$. Figure 2 shows the deposited film on top of the limiter in its interference colours based on colour fringe analysis. Clearly visible is the localized pattern near the injection hole resulting from Si injection. The distortion of the deposit relative to the magnetic field line can be explained by $\mathrm{E} \times \mathrm{B}$ drift.

An additional $\mathrm{SiD}_{4}$ injection experiment has been carried out with graphite roof-like test limiter pre-deposited with an aluminium layer. With ohmic plasma conditions and the edge of the limiter located at the LCFS, silane $\mathrm{SiD}_{4}$ has been injected in 13 discharges with an 
injection rate of $\sim 1 \times 10^{20}$ per discharge. Post-mortem analysis of the limiter surface by colour fringe analysis and EPMA did result in local Si deposition efficiency of $\sim 0.1 \%$.

\subsection{Hydrocarbon $\left({ }^{13} \mathrm{CH}_{4},{ }^{13} \mathrm{C}_{2} \mathrm{H}_{4}\right)$ injection through test limiter}

End of the 1990s pioneering injection experiment using ${ }^{13} \mathrm{C}$ marked methane has been carried out at TEXTOR. As TEXTOR is a carbon device and thus contains carbon ${ }^{12} \mathrm{C}$ as plasma impurity, injection of ${ }^{13} \mathrm{C}$ marked methane allows for distinguishing local deposition resulting from injection and carbon ${ }^{12} \mathrm{C}$ deposition resulting from plasma background.

The first ${ }^{13} \mathrm{CH}_{4}$ injection experiment has been carried out with a graphite roof-like limiter covered with an aluminium plate [4]. With the edge of the limiter located at the LCFS, ohmic discharges have been applied. After three discharges without ${ }^{13} \mathrm{CH}_{4}$ injection a puffing rate of $\sim 5 \times 10^{19}{ }^{13} \mathrm{CH}_{4}$ per discharge for the following 18 shots has been used. Light emission of CII and $\mathrm{CH}$ has been observed in 2D poloidally integrated with $\mathrm{CCD}$ camera. Between the discharges the deposition pattern on the limiter was monitored with a camera - an example showing the localized deposition after the $5^{\text {th }}$ injection is shown in figure 3. Applying various post-mortem analysis techniques (Secondary Ion Mass Spectroscopy - SIMS, Nuclear Reaction Analysis - NRA, Elastic Recoil Detection Analysis - ERDA, colorimetry) did result in a local ${ }^{13} \mathrm{C}$ deposition efficiency of about $\mathbf{0 . 2 \%}$. From measurements on a collector probe on the side surface of the test limiter it has been concluded that ${ }^{13} \mathrm{C}$ not re-deposited locally feeds the SOL carbon flux and eventually ends up on other locations within TEXTOR.

Later on, further ${ }^{13} \mathrm{CH}_{4}$ injection experiments have been carried out to study the influence of substrate material and roughness as well as plasma parameter. Roof-like limiters with surface plates of tungsten, molybdenum and graphite of similar roughness have been exposed to comparable ohmic plasma conditions with their tips located at the LCFS [5]. For each limiter about 10 discharges with ${ }^{13} \mathrm{CH}_{4}$ injection of $\sim 8 \times 10^{19}$ molecules per discharge were performed. Extensive post-mortem analysis with SIMS, colorimetry and NRA delivered local 
${ }^{13} \mathrm{C}$ deposition efficiencies of $\mathbf{0 . 1 1 \%}$ for tungsten, $\mathbf{0 . 1 4 \%}$ for molybdenum and $\mathbf{0 . 1 7 \%}$ for graphite showing a clear influence of substrate material: increasing atomic mass of substrate material leads to smaller deposition efficiency. The deposition affected areas did not differ significantly.

The influence of substrate material and surface roughness has been studied in [6] using spherical test limiters of graphite and tungsten. To study the effect of plasma conditions ohmic plasmas have been compared to NBI (Neutral Beam Injection) heated ones. For ohmic conditions the top of the limiters was located $10 \mathrm{~mm}$ outside the LCFS, for NBI ones $20 \mathrm{~mm}$. The tungsten and the polished graphite limiters had a roughness of $\sim 0.1 \mu \mathrm{m}$. The roughness of the unpolished graphite limiters was 10 times larger. Injection of ${ }^{13} \mathrm{CH}_{4}$ has been performed with a rate of $\sim 10^{18}$ molecules per second for $6-10$ discharges. Resulting local deposition efficiencies determined by colorimetry, SIMS and NRA vary between $\mathbf{0 . 3 \%}$ and 9\%. Largest ${ }^{13} \mathrm{C}$ deposition has been observed for unpolished graphite limiter under ohmic conditions, lowest one for tungsten under NBI conditions. The deposition pattern covered a larger area on rough graphite compared to polished one and was most localized on tungsten surfaces.

Besides methane also ethylene ${ }^{13} \mathrm{C}_{2} \mathrm{H}_{4}$ injection experiments have been performed employing spherical tungsten and (polished) graphite limiter of similar roughness $0.1 \mu \mathrm{m}$. With ohmic plasma conditions the top of the limiters were located $12 \mathrm{~mm}$ outside the LCFS. With each limiter 10 discharges applying an injection of $\sim 5 \times 10^{18}$ molecules per second have been performed. In addition to spectroscopy of $\mathrm{CH}$ and $\mathrm{CII}$, also light from $\mathrm{C}_{2}$ molecules has been monitored. NRA analysis did result in a local ${ }^{13} \mathrm{C}$ deposition of $\mathbf{1 . 2 \%}$ for tungsten and 2.1\% for graphite. The area of deposition from ${ }^{13} \mathrm{C}_{2} \mathrm{H}_{4}$ injection was larger on graphite than on tungsten, however, there was no large difference compared to ${ }^{13} \mathrm{CH}_{4}$ injection. 


\subsection{Tungsten-hexafluoride $\left(\mathrm{WF}_{6}\right)$ injection through test limiter}

Recently, $\mathrm{WF}_{6}$ has been injected through a roof-like limiter covered with a polished graphite plate. During 7 NBI-heated discharges $3 \times 10^{19} \mathrm{WF}_{6}$ molecules/discharge have been injected with the top of the limiter positioned $15 \mathrm{~mm}$ outside the LCFS. At the beginning of the experiment the limiter tip was located at the LCFS, whereas due to large power flux the edges of the graphite plate did break off, see figure 4. During the exposures light emission from neutral tungsten and fluorine has been monitored. After demounting the limiter various surface analysis methods have been applied (SIMS with profilometry, EPMA, NRA and colour fringe analysis). The local deposition efficiency of tungsten on the graphite plate has been estimated to $\sim \mathbf{1 \%}$. However, significant amount of tungsten has been found in the shadows caused by the broken edges of the graphite plate (about $50 \%$ of $\mathrm{W}$ the total $\mathrm{W}$ deposited on the plate itself). Obviously tungsten could accumulate in these plasmashadowed regions. About $30 \%$ of the injected $\mathrm{W}$ could be found by post mortem analysis on the ALT toroidal limiter, extrapolated from 2 tiles analysed.

\subsection{Summary of test limiter injection experiments}

Table 1 summarises the measured local deposition efficiencies of all 16 injection experiments in TEXTOR with test limiters. All experiments show remarkably small deposition efficiencies - largest deposition efficiency of $9 \%$ has been found for ${ }^{13} \mathrm{CH}_{4}$ injection through unpolished, spherical $\mathrm{C}$ test limiter and ohmic plasma conditions. The following main conclusions can be drawn from methane injection experiments:

- deposition efficiency on smooth surfaces is smaller than on rough ones (up to factor 5)

- deposition efficiency on metal surfaces is smaller than on graphite (up to factor 4)

- ohmic plasmas lead to larger deposition efficiency than NBI-heated ones (up to factor 2)

- roof-like limiters tend to smaller deposition efficiency than spherically shaped ones. 
Ethylene leads to local deposition efficiency about 50\% larger than from methane injection. The local deposition efficiency for silane seems to be similar to the one for methane under comparable conditions. The first experiment with $\mathrm{WF}_{6}$ using roof-like test limiter also shows small local deposition efficiency of only about $1 \%$, however, with a tendency of being larger compared to hydrocarbon injection.

\subsection{Methane $\left(C_{4}\right)$ injection through carrier front plate}

New injection experiments with test limiters exposed to the edge plasma near the LCFS as described above study formation of re-deposited layers at plasma-wetted areas. To study the re-deposition and re-erosion of injected methane at remote, i.e. almost plasma-shadowed areas, a cylinder with a carrier front plate (CFP) equipped with injection hole and Quartz Micro Balance (QMB) has been exposed to the far SOL of TEXTOR [7]. Figure 5 shows the geometry of the cylinder with its CFP parallel to the B field minimizing the impinging ion flux to the top surface. The $\mathrm{QMB}$, about $1 \mathrm{~cm}$ recessed from the CFP, measures deposition/erosion on a shot-to-shot basis. The cylinder has been exposed to ohmic and NBIheated plasmas. A scan of radial position of the CFP has been performed while applying $\mathrm{CD}_{4}$ injection with a rate of $2.5 \times 10^{20}$ molecules/discharge. The right part of figure 5 shows resulting local deposition efficiencies on the QMB in dependence on radial position. Deposition efficiency on the QMB varies between 0.002 and $0.008 \%$. It increases if the CFP is located deeper in the plasma and is slightly larger for NBI than for ohmic discharges. More details of this experiment will be presented in [7]. In chapter 3 of the present paper according modelling of the deposition efficiency on the QMB will be shown and discussed with respect to enhanced re-erosion of re-deposits. 


\section{Modelling of TEXTOR injection experiments}

Extensive modelling of the various injection experiments has been performed with the three-dimensional Monte Carlo impurity transport code ERO [8]. A brief summary of former modelling results will be presented and then some new aspects including first modelling attempts for the $\mathrm{WF}_{6}$ test limiter injection and $\mathrm{CD}_{4}$ nozzle experiment.

\section{Silane $\mathrm{SiD}_{4}$ injection:}

Modelling of $\mathrm{SiD}_{4}$ injection through spherical steel test limiter is discussed in [9]. Applying full sticking for $\mathrm{SiD}_{\mathrm{x}}$ species and neglecting erosion of deposited $\mathrm{Si}$ results in a local deposition efficiency of about $90 \%$ showing that a large number of injected species returns to the limiter. Assuming more realistic assumptions for reflection of $\mathrm{SiD}_{\mathrm{x}}$ species ( $\mathrm{R}=0.7$ for charged and $\mathrm{R}=0.995$ for neutral species) and including re-erosion by physical sputtering due to the background plasma decreases the local deposition efficiency to about $65 \%$ - this is about one order of magnitude larger than the experimental one $(<5 \%)$. As possible mechanism to reduce the local deposition efficiency, a parallel (to the magnetic field) electric field generated by the strong local impurity source of injected particles has been discussed. This electric field can drive positively charged species away from the limiter surface and thus reduces the modelled local deposition efficiency from $65 \%$ to $35 \%$ - still at least a factor of 7 larger than in the experiment. Recently, more detailed studies concerning the influence of the local impurity source on the plasma (possible decrease of electron temperature, increase of electron density and parallel electric field) have been performed [10] for ${ }^{13} \mathrm{CH}_{4}$ injection experiments. The results indicate that large injection sources (about 10 times larger than in the experiments) could reduce the local electron temperature but also increase the density - therefore there is no large effect on the local deposition efficiency. A parallel electric field sufficient to significantly decrease the local deposition efficiency would in turn lead to disagreements between measured and modelled light emission distributions. 


\section{Methane ${ }^{13} \mathrm{CH}_{4}$ injection:}

Also modelling of methane injection results in much larger local deposition efficiencies compared to the experiment if "standard" assumptions are used for hydrocarbon sticking and re-erosion of re-deposited carbon [11]. Whereas the local ${ }^{13} \mathrm{C}$ deposition efficiency for the roof-like limiter has been measured to be $\sim 0.2 \%$, the modelling results in about $40 \%$ if neutral hydrocarbons are assumed to be fully reflected, $\mathrm{R}_{\text {neutral }}=1$, and charged hydrocarbons with $\mathrm{R}_{\text {ion }}=0.5$. For carbon atoms the reflection is calculated according to TRIM. However, the spatial distribution of measured and observed light emission ( $\mathrm{CH}$ and $\mathrm{CII}$ ) agrees well. If $\mathrm{R}=1$ is assumed also for charged hydrocarbons, the local ${ }^{13} \mathrm{C}$ deposition efficiency is lowered to $\sim 14 \%$. Fully reflection of hydrocarbons has been interpreted as "effective self-erosion of the carbon deposits formed by hydrocarbons having incorporated the hydrogen in the species itself". However, to further decrease the modelled local deposition efficiency to match the observed value, an enhanced re-erosion of re-deposited carbon by the background plasma has been proposed. The erosion yield for carbon re-deposits should be a factor of up to 10 larger than the "normal" erosion yield for substrate carbon. At that time this enhanced re-erosion has been attributed to chemical erosion.

In addition to ERO modelling, also calculations of ${ }^{13} \mathrm{CH}_{4}$ injection through roof-like limiter with the EDDY code have been carried out [12]. Very similar to ERO, also EDDY has to make extreme assumptions for hydrocarbon sticking (negligible) and enhanced re-erosion of re-deposited carbon to reproduce the measured local ${ }^{13} \mathrm{C}$ deposition efficiency of $\sim 0.2 \%$.

The observed local dependence of ${ }^{13} \mathrm{C}$ deposition efficiency on substrate material has been addressed with ERO-SDTrimSP calculations of ${ }^{13} \mathrm{CH}_{4}$ injection through spherically shaped graphite and tungsten test limiters under NBI-heated plasmas [13]. The coupled version ERO-SDTrimSP has been applied for these experiments to properly describe surface mixing effects arising from atoms of different masses (W and C). Figure 6 shows modelled 
${ }^{13} \mathrm{C}$ distribution patterns on top of graphite and tungsten limiter including modelled and corresponding observed ${ }^{13} \mathrm{C}$ deposition efficiency. The experiment has been carried out with "naturally smooth" tungsten limiter and unpolished, rough graphite limiter. As discussed above, also this modelling needs negligible sticking for hydrocarbons and enhanced background (chemical) erosion of re-deposited carbon ( $\sim 10$ times compared to graphite erosion) to approach the low measured local deposition efficiencies. With these assumptions, however, good agreement between modelling and experiment is achieved for the tungsten limiter. The ERO-SDTrimSP simulation for the graphite limiter shows factor 2 smaller deposition efficiency and more located pattern than the experiment. ERO-SDTrimSP does not take into account rough surfaces, which are known to increase the deposition efficiency compared to smooth ones, see paragraph 2. As seen in Table 1, using polished graphite limiter under similar exposure conditions reduces the local ${ }^{13} \mathrm{C}$ deposition efficiency to $1.3 \%$, which is very similar to the modelling $(1.8 \%)$. The substrate dependence can be understood in terms of more effective reflection of plasma deuterium ions at heavy (compared to carbon) tungsten atoms leading to larger deuterium flux back to the surface, which finally is able to effectively erode re-deposited layers on top. Also the reflection of incoming carbon atoms is larger on tungsten than on graphite. The modelling also indicates the influence of limiter geometry: the local ${ }^{13} \mathrm{C}$ deposition efficiency is larger on spherical than on roof-like test limiters, which can be explained by more shallow magnetic field angle in case of the spherical geometry reducing the effective plasma ion flux to the area of ${ }^{13} \mathrm{C}$ deposition.

\section{Ethylene ${ }^{13} \mathrm{C}_{2} \mathrm{H}_{4}$ injection:}

ERO modelling of ${ }^{13} \mathrm{C}_{2} \mathrm{H}_{4}$ injection through spherical graphite (polished) and tungsten test limiter under ohmic plasma conditions has been published in [14]. Very good agreement has been obtained in local ${ }^{13} \mathrm{C}$ deposition efficiency and pattern if low sticking of hydrocarbons and enhanced re-erosion of carbon re-deposits is assumed. The larger local ${ }^{13} \mathrm{C}$ 
deposition from ${ }^{13} \mathrm{C}_{2} \mathrm{H}_{4}$ compared to ${ }^{13} \mathrm{CH}_{4}$ injection could be explained by differences in the rate coefficients in the reactions chains and the larger mass (i.e. smaller velocity) of the higher hydrocarbons.

\section{Tungsten-hexafluoride $\mathrm{WF}_{6}$ injection:}

Due to the lack of dissociation and ionization data for $\mathrm{WF}_{6}$ the $\mathrm{ERO}$ modelling has been performed with injection of thermal tungsten atoms $\mathrm{W}^{0}$. To reproduce the measured radial penetration of WI light from injected $\mathrm{WF}_{6}$, the ionisation rate coefficient for injected $\mathrm{W}^{0}$ has been reduced in the modelling. Obviously, this approach does not consider the dissociation of $\mathrm{WF}_{6}$ to $\mathrm{WF}_{\mathrm{x}}$ species, from which certain amount could return to the limiter before becoming $\mathrm{W}^{0}$. Therefore, modelled $\mathrm{W}$ re-deposition represents a lower limit. The modelled local $\mathrm{W}$ deposition efficiency is $11 \%$ and therefore at least a factor of 10 larger than the measured one $(\sim 1 \%)$. Tungsten sputtering is done by impurities rather than by deuterium. In the modelling it has been assumed that the plasma contains $1 \%$ oxygen and 5\% carbon at the LCFS. However, after dissociation of $\mathrm{WF}_{6}$, ionised fluorine atoms can return to the surface and contribute to tungsten sputtering too. To consider this additional sputter source the following extreme assumption has been done: if a $\mathrm{W}$ atom from injection returns to the surface also $6 \mathrm{~F}$ atoms return and sputter tungsten with a yield of $5 \%$. This process decreases the local $\mathrm{W}$ deposition efficiency to $\sim 8 \%$, which is still significantly larger than the measured one. To further decrease $\mathrm{W}$ deposition, 5 times enhanced sputtering due to the background plasma has been applied leading to a local deposition efficiency of $\sim 3 \%$. Figure 7 shows the modelled 2D pattern of $\mathrm{W}$ deposition and a comparison of modelled and measured $\mathrm{W}$ profiles. It can be concluded that also in case of $\mathrm{WF}_{6}$ injection the modelling has to assume enhanced re-erosion of re-deposited tungsten - in this case physical sputtering - to approach the small local deposition efficiency as observed experimentally. 


\section{Conclusions from test limiter injection experiments:}

Modelling of the $\mathrm{WF}_{6}$ injection experiment indicates the importance of re-erosion of deposited tungsten due to $\mathrm{F}$ atoms from the injected molecules. So far, possible erosion due to $\mathrm{H}$ atoms from injected hydrocarbons has not been taken into account directly. Instead, large reflection coefficients for hydrocarbon species returning to the surface have been assumed to lower the modelled ${ }^{13} \mathrm{C}$ deposition. Thus, new modelling has been performed assuming more sophisticated ("realistic") reflection coefficients for hydrocarbons and taking into account erosion due to $\mathrm{H}$ atoms from injection. Using the example of ${ }^{13} \mathrm{CH}_{4}$ injection through roof-like limiter exposed to ohmic plasmas, ERO modelling has been carried out assuming $\mathrm{R}=1$ for neutral and $\mathrm{R}=0.1$ for charged hydrocarbons ${ }^{13} \mathrm{CH}_{\mathrm{x}}$. Neutral hydrocarbons have low energy and therefore large reflection whereas charged species are accelerated in the sheath potential resulting in energies of $3 \mathrm{~T}_{\mathrm{e}}$ and thus much smaller reflection [15]. Hydrogen is not followed in ERO wherefore the following, extreme assumption is made for $\mathrm{H}$ atoms returning to the surface: an injected ${ }^{13} \mathrm{CH}_{\mathrm{x}}$ returning to the surface is accompanied by $4 \mathrm{H}$ atoms. This returning $\mathrm{H}$ flux erodes re-deposited carbon with a yield of $20 \%$ (this could be physical and/or chemical erosion). In addition, enhanced re-erosion of re-deposited carbon due to background plasma is addressed with enhancement factors for physical and chemical erosion. Table 2 summarises the resulting local ${ }^{13} \mathrm{C}$ deposition efficiencies, which have to be compared with the experimental value of $0.2 \%$. Although large re-erosion of re-deposits due to injected $\mathrm{H}$ atoms has been assumed, the resulting local deposition efficiency without additional enhanced erosion due to background plasma is $13 \%$ and thus much larger than measured.

The modelling of impurity injection through test limiters exposed to the SOL of TEXTOR suggest that under simultaneous ion fluxes re-deposited species suffer from much 
larger re-erosion than substrate material. This has been concluded for carbon, but also for silicon and tungsten, which are not subject to chemical erosion.

\section{Methane $\mathrm{CD}_{4}$ injection through carrier front plate:}

Modelling has been performed for ohmic plasma conditions with the carrier front plate (CFP) located at various radial positions deeply in the limiter shadow of TEXTOR with the QMB detector in a shadowed region and the surrounding CFP parallel to the field lines. To calculate the carbon flux returning to the CFP, all species from injection impinging the CFP surface are assumed to stick. Due to magnetic field parallel to CFP surface and positioning of the CFP deeply in the SOL erosion and deposition due to background plasma is neglected. Also the erosion due to deuterium from injected species is at first neglected. The right part of figure 5 shows the so-modelled deposition efficiencies in comparison to the experiment. The radial dependence is reproduced by the modelling, whereas modelled values are $\sim 20$ times larger than measured ones. However, the modelling did calculate the incoming flux of particles. More detailed calculations of the impurity transport inside the QMB box with the 3D-GAPS code [16] show that only a part of particles entering the aperture to the QMB finally can reach the QMB quartz itself [7]. Also, the ERO modelling shows that almost all particles returning to the CFP are neutrals with small energies below $3 \mathrm{eV}$ and thus large reflection coefficients [15]. This and a possible re-erosion due to deuterium from the injection finally reduce the modelled deposition efficiency to values as observed. One thus can conclude that the re-deposition at remote, plasma-shadowed areas can be understood without assuming enhanced re-erosion of re-deposits as it was necessary for layers at plasma-wetted areas. 


\section{Conclusions}

Injection of various species $\left(\mathrm{SiD}_{4},{ }^{13} \mathrm{CH}_{4},{ }^{13} \mathrm{C}_{2} \mathrm{H}_{4}, \mathrm{WF}_{6}\right)$ through test limiters exposed to the SOL of TEXTOR show in general very low local deposition efficiency on the test limiter surfaces. The various experiments have been modelled with the impurity transport code ERO and partly with EDDY. The modelling can reproduce well the observed light emission (such as $\mathrm{CH}$ and $\mathrm{CII}$ from hydrocarbon injection, $\mathrm{SiH}$ and $\mathrm{SiII}$ from $\mathrm{SiD}_{4}$ injection and also WI resulting from sputtering), which indicates that the impurity transport is described reasonably well. If the modelling uses standard assumptions for sticking of returning species and for reerosion of re-deposited species, the modelled local deposition efficiency is in all cases significantly larger than the observed one, between factor of 10- 100. Erosion due to atoms incorporated in the injected molecules $\left(\mathrm{H}\right.$ for hydrocarbon and silane injection and $\mathrm{F}$ for $\mathrm{WF}_{6}$ injection) has been considered and leads to some decrease of deposition efficiency but still much too large compared to experiment. In summary, the observed low local deposition efficiencies is attributed to an enhanced re-erosion of re-deposited species due to background plasma - typically a factor of 5 to 10 larger than erosion of according substrate material. This could be attributed to chemical and physical erosion for carbon but must be due to physical sputtering solely in case of silicon and tungsten. It is therefore concluded that re-deposited species suffer from enhanced re-erosion at plasma-wetted areas under simultaneous ion bombarding.

Additional processes have been discussed as possible explanation for low local deposition: the flux of injected molecules could lead to local disturbance of the plasma (cooling together with increase of electron density and also generation of parallel electrical field). However, measurements with Langmuir probe near injection cloud (not for test limiter experiment but gas inlet) and also spectroscopic observations of line ratios indicate plasma disturbance of less than $15 \%$ [17]. Also, first simulations using a 1D fluid model to address 
possible plasma disturbances indicate that such effects cannot explain the observed very low deposition efficiencies and in addition lead to large discrepancies with experimental light emission patterns [10].

Furthermore, it has been demonstrated that the observed re-deposition and re-erosion at remote areas, which are shadowed from plasma ion flux, can be understood without assumption of enhanced re-erosion. This has been observed on shadowed areas on the limiter during $\mathrm{WF}_{6}$ injection (broken edges) and also in a special $\mathrm{CD}_{4}$ injection experiment using a cylinder with its surface parallel to magnetic field and located in the far SOL. This indicates that enhanced re-erosion of re-deposited layers is specific for layers growing at plasmawetted layers under simultaneous impact of energetic ions.

ERO simulations of ${ }^{13} \mathrm{CH}_{4}$ injection experiments in the divertor of JET are also in line with the need of enhanced re-erosion and small sticking of hydrocarbons [18]. According simulations for AUG are presented in [19].

The effect of enhanced re-erosion could significantly increase the net-erosion of the main wall in ITER due a decrease of the effective local re-deposition probability by an effective reerosion of re-deposits. As e.g. demonstrated in [20] the effect should be less pronounced in the divertor of ITER, since the divertor is more closed and re-deposition occurs multistepwise, which in the overall increases re-deposition. This indeed is seen also in present experiments by the larger (compared to TEXTOR experiments) ${ }^{13} \mathrm{C}$ deposition efficiencies from ${ }^{13} \mathrm{CH}_{4}$ injection into the divertors of JET and AUG.

\section{Acknowledgements}

This work, supported by the European Communities under the contract of Association between EURATOM/FZJ, was carried out within the framework of EFDA. The views and 
opinions expressed herein do not necessarily reflect those of the European Commission. CPU time for computations has been provided by JSC (Jülich Supercomputer Centre).

\section{References}

[1] P.C. Stangeby et al., these proceedings

[2] H.G. Esser et al., J. Nucl. Mat. 220-222 (1995) 457

[3] F. Weschenfelder et al., Plasma Phys. Control. Fus. 38 (1996) A311

[4] P. Wienhold et al., J. Nucl. Mat. 290-293 (2001) 362

[5] A. Kreter et al., J. Nucl. Mat. 363-365 (2007) 179

[6] A. Kreter et al., Plasma Phys. Control. Fus. 50 (2008) 095008

[7] H.G. Esser et al., these proceedings

[8] A. Kirschner et al., Nucl. Fus. 40, No. 5 (2000) 989

[9] U. Kögler et al., J. Nucl. Mat. 241-243 (1997) 816

[10] R. Ding et al., these proceedings

[11] A. Kirschner et al., J. Nucl. Mat. 328 (2004) 62

[12] K. Ohya et al., Physica Scripta T138 (2009) 014010

[13] S. Droste et al., Plasma Phys. Control. Fus. 50 (2008) 015006

[14] R. Ding et al., Plasma Phys. Control. Fus. 52 (2010) 045005

[15] K. Ohya, private communication

[16] D. Matveev, these proceedings

[17] S. Brezinsek et al., J. Nucl. Mat. 363-365 (2007) 1119

[18] M. Airila et al., Physica Scripta T138 (2009) 014021

[19] L. Aho-Mantila et al., these proceedings

[20] A. Kirschner et al., Physica Scripta, Vol. T138 (2009) 014011 


\section{Figure captions}

Figure 1. Experimental set-up in TEXTOR and typical test limiter geometries.

Figure 2. Deposition pattern on spherical steel limiter after $\mathrm{SiD}_{4}$ injection based on colour fringe analysis.

Figure 3. False colour picture of deposition pattern (to the right of injection hole) on rooflike graphite limiter with aluminium plate after $5^{\text {th }}$ injection of ${ }^{13} \mathrm{CH}_{4}$.

Figure 4. $\mathrm{WF}_{6}$ injection experiment: roof-like test limiter after exposure to NBI heated plasmas.

Figure 5. Cylinder with carrier front plate, equipped with injection hole and QMB, located in far SOL. Measured and modelled deposition efficiency on $\mathrm{QMB}$ from $\mathrm{CD}_{4}$ injection in dependence on radial position of nozzle inside SOL. In the modelling fully sticking for all species has been assumed.

Figure 6. Modelled ${ }^{13} \mathrm{C}$ deposition after ${ }^{13} \mathrm{CH}_{4}$ injection through spherically shaped graphite and tungsten test limiter. The solid lines indicate the expansion of the experimental deposition pattern.

Figure 7. Modelled 2D pattern of $\mathrm{W}$ deposition from $\mathrm{WF}_{6}$ injection and comparison of normalised modelled and measured $\mathrm{W}$ profile in toroidal direction.

Table 1. Deposition efficiencies from injection experiments with test limiters in TEXTOR. Ohmic and NBI plasma conditions.

Table 2. Modelled local deposition efficiencies from ${ }^{13} \mathrm{CH}_{4}$ injection through roof-like limiter. Assumptions for hydrocarbon reflection: $\mathrm{R}_{\text {neutral }}=1, \mathrm{R}_{\mathrm{ion}}=0.1$. Erosion yield for redeposited carbon due to $\mathrm{H}$ atoms from injected molecules: $\mathrm{Y}_{\mathrm{H}-\mathrm{C}}=20 \%$. Experimental local deposition efficiency: $0.2 \%$. 


\section{Figures:}
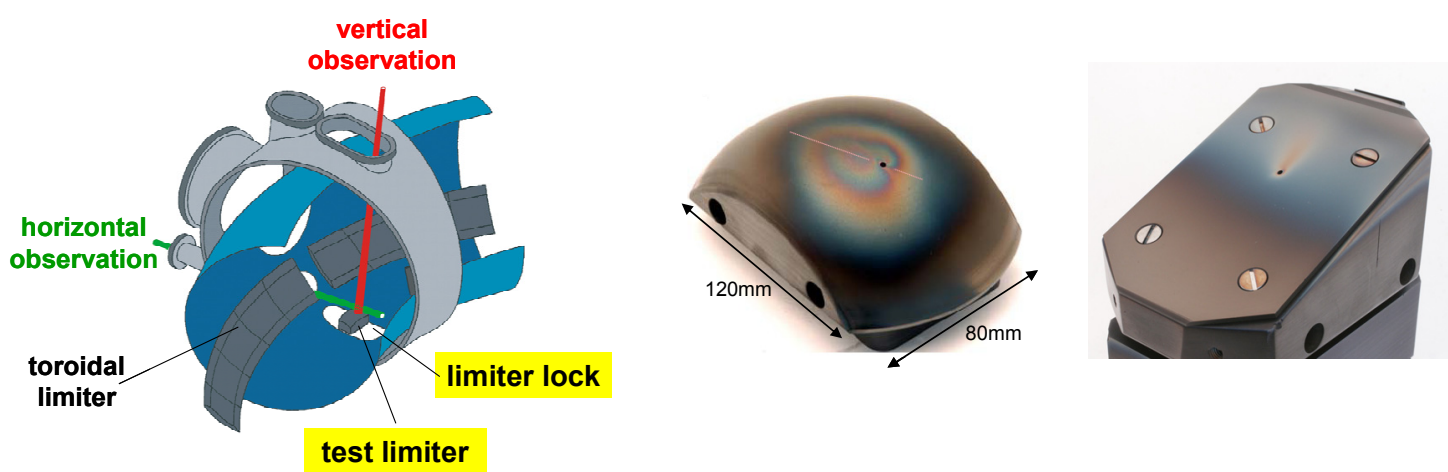

Figure 1

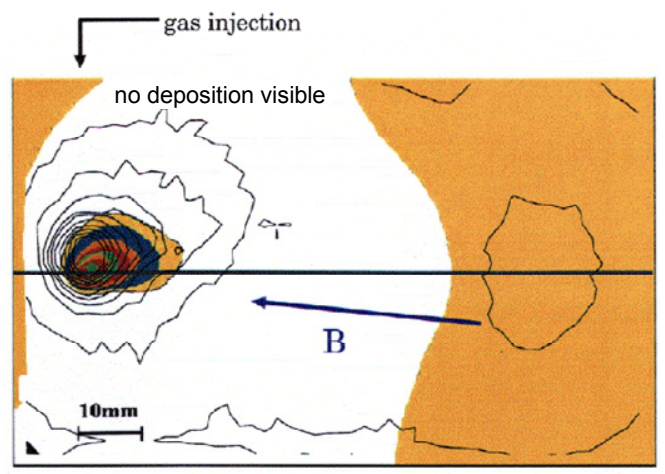

Figure 2

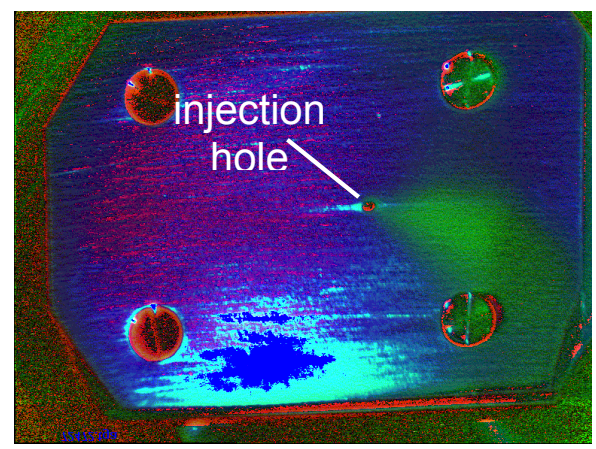

Figure 3 


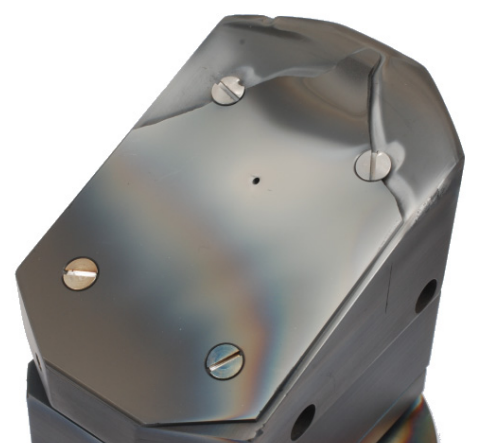

Figure 4
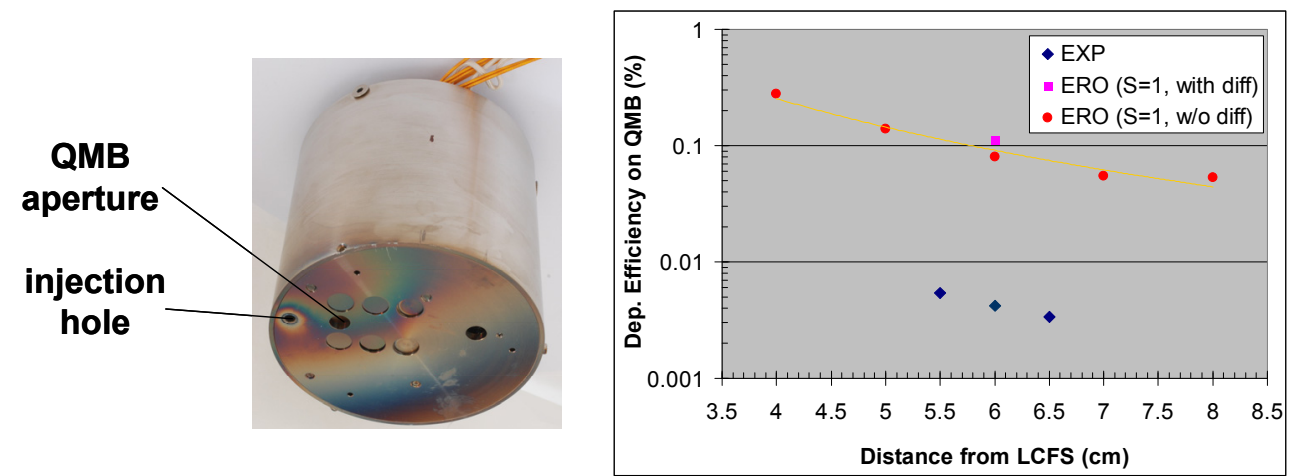

Figure 5
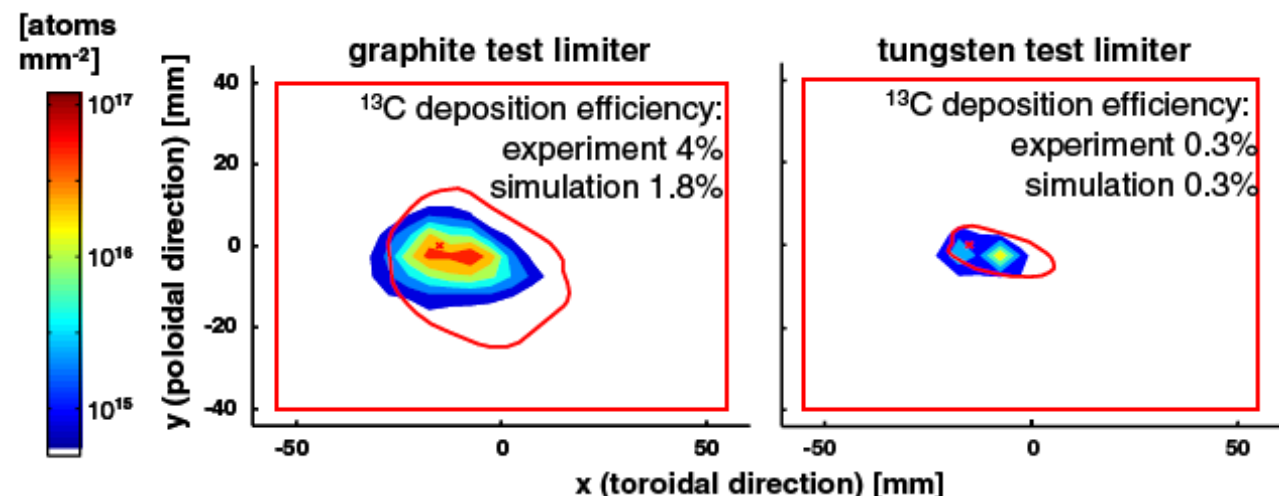

Figure 6 

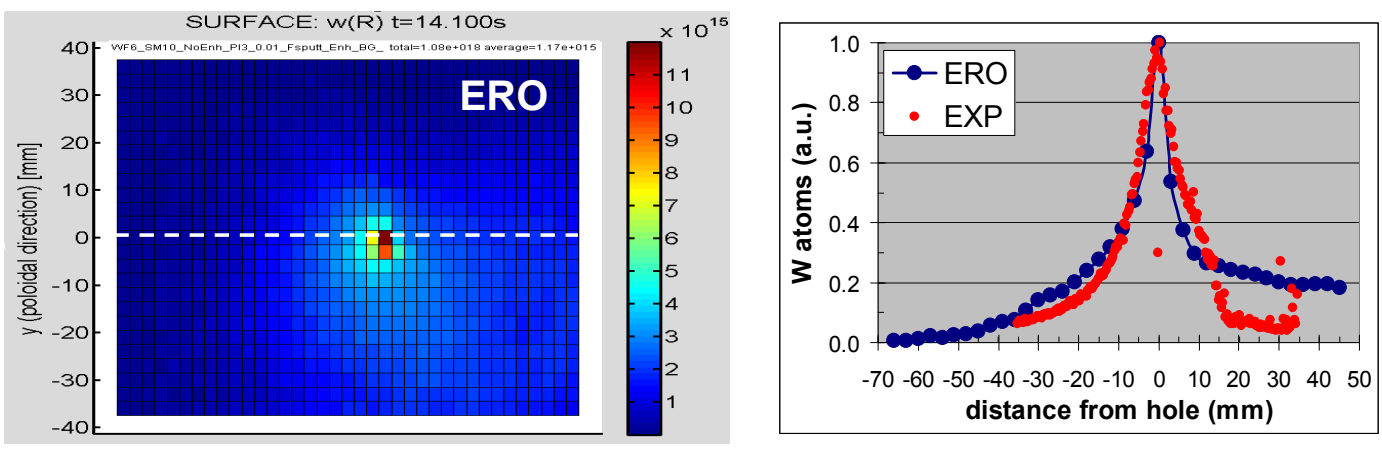

Figure 7

\begin{tabular}{|c|c|c|c|c|c|c|c|c|}
\hline & \multicolumn{4}{|c|}{ spherical } & \multicolumn{4}{|c|}{ roof-like } \\
\hline limiter & $\mathbf{F e}$ & $\mathbf{w}$ & Mo & C & $\mathbf{F e}$ & $\mathbf{w}$ & Mo & C \\
\hline $\mathrm{SiD}_{4}$ & $<5 \%$ & & & $4-5 \%$ & & & & $0.1 \%(\mathrm{Al})$ \\
\hline${ }^{13} \mathrm{CH}_{4}$ & & $0.8 \%$ & & $9 \%$ & & $0.11 \%$ & $0.14 \%$ & $0.2 \%(\mathrm{Al})$ \\
\hline & & $0.3 \%$ & & $1.7 \%$ (pol.) & & & & $0.17 \%$ (pol.) \\
\hline & & & & $4 \%$ & & & & \\
\hline & & & & $1.3 \%$ (pol. $)$ & & & & \\
\hline${ }^{13} \mathrm{C}_{2} \mathrm{H}_{4}$ & & $1.2 \%$ & & $2.1 \%$ (pol.) & & & & \\
\hline $\mathbf{W F}_{6}$ & & & & & & & & $\sim 1 \%$ (pol.) \\
\hline
\end{tabular}

Table 1

\begin{tabular}{|c|c|r|}
\hline factor_phys & factor_chem & $\begin{array}{c}\text { 13C deposition } \\
\text { efficiency }\end{array}$ \\
\hline 1 & 1 & $\sim 13 \%$ \\
\hline 5 & 5 & $\sim 0.5 \%$ \\
\hline 10 & 10 & $<0.2 \%$ \\
\hline
\end{tabular}

Table 2 